$\mathbb{T}$ periodica polytechnica

\author{
Transportation Engineering \\ $38 / 2(2010) 79 \sqrt{84}$ \\ doi: 10.3311/pp.tr.2010-2.04 \\ web: http://www.pp.bme.hu/tr \\ (c) Periodica Polytechnica 2010
}

RESEARCH ARTICLE

\section{Investigating the emission trends of road freight vehicles}

\author{
Rita Markovits Somogyi / Ádám Török
}

Received 2009-11-03

\begin{abstract}
This research paper provides an overview of road transport freight vehicle emissions with the purpose to provide an outlook for vehicle emissions trends and standards. It describes the impact of vehicle emissions and assesses the adequacy of emission limits adopted for new passenger car engines and for heavy-duty diesel engines. It briefly outlines the Jevons paradox indicating its importance in the field of fuel efficiency. Finally a new real time method for the assessment of $\mathrm{CO}_{2}$ emissions as a function of the individual goods transported is also reported here.
\end{abstract}

\section{Keywords}

$\mathrm{CO}_{2}$ emission $\cdot$ emission trends $\cdot$ road freight vehicles

\section{Acknowledgement}

This work is connected to the scientific program of the "Development of quality-oriented and harmonized $R+D+I$ strategy and functional model at BME" project. This project is supported by the New Hungary Development Plan (Project ID: TÁMOP4.2.1/B-09/1/KMR-2010-0002).

\section{Rita Markovits Somogyi}

Department of Transport Economics, BME, H-1111 Budapest Bertalan L. u. 2., Hungary

\section{Ádám Török}

Department of Transport Economics, BME, H-1111 Budapest Bertalan L. u. 2., Hungary

e-mail: atorok@kgazd.bme.hu

\section{Introduction}

Continuing air quality problems from vehicle related pollution have been stimulating innovative pollution control approaches around the world. As these approaches are implemented, steady progress is made in reducing air pollution problems. However, the vehicle population and kilometres travelled by vehicles continues to increase, especially in the new members of the EU. To keep pace with this growth while lowering vehicle pollution even more, the EU is continuing to develop even tighter controls for the coming years [1]. In Europe, European Union light and heavy-duty vehicle and internal combustion engine standards have been substantially tightened over the past few years. There has been a conscious decision to set less stringent standards for diesel fuelled cars than for gasoline fuelled cars in recognition of the superior fuel economy potential of diesel vehicles. One response to reducing greenhouse gases has been to increase the use of highly efficient diesels in the passenger car and light truck sectors. However, these vehicles emit higher amounts of $\mathrm{NO}_{x}$ and particulate matter than the gasoline fuelled alternatives. Further, some evidence indicates that currently applied technologies which reduce the mass of particulate matter emitted may result in an increase in the number of very small particles. Since smaller particles have the potential to be ingested more deeply into the lung than larger particles, they may actually be more hazardous. The three primary drivers leading to increases in the world's vehicle fleets are population growth, increased urbanisation and economic improvement. According to the United Nations, the global population increased from approximately 2.5 billion people in 1950 to 6 billion people in late 1999 and it is projected to increase by an additional $50 \%$ to 9 billion by 2050 . This growth will not be evenly distributed but will be concentrated outside of the OECD, in Asia, Africa and Latin America. Simultaneously, all regions of the world continue to urbanise with the greatest increases expected in Southeast Asia, and South and South West Asia. This is significant since per capita vehicle populations are greater in urban than in rural areas. According to the OECD, annual GDP growth rates over the next two decades will be highest in China, East Asia, Central and Eastern Europe and the former Soviet Union 
which will stimulate growth in vehicle populations in these regions. Worldwide, cars, trucks, buses, and other motor vehicles continue to play a dominant role in causing air pollution. In the European Union as a whole, road vehicles are the largest source of $\mathrm{CO}, \mathrm{NO}_{x}$ and non-methane hydrocarbons [2]. Prior to the adoption of the Euro 3/4 requirements, forecasts indicated that vehicles would remain a major emissions source out to 2030 . In densely populated urban areas, vehicles can be a major source of exposure to particulates as well. Currently, road vehicles account for $74 \%$ of nitrogen oxides and $94 \%$ of black smoke emissions in London. On their own, diesels account for $32 \%$ and $87 \%$ of total emissions ( $43 \%$ and $92 \%$ of vehicle emissions) for these two pollutants respectively [3]. Further, when focusing on emissions in congested city centres, the importance of vehicle emissions is even greater. In this instance, diesel bus emissions appeared to be the primary source.

\section{Rapid progress in emissions controls}

Legislators in most regions of the world have been significantly tightening their motor vehicle regulations to address the environment and health concerns described above. Major recent developments are summarised below. The European Commission set up the European Auto-Oil Program in 1994 with the European associations for the car industry (ACEA) and the oil industry, to provide the technical basis for the development of EU policy towards road vehicle emissions. The first phase of the programme was completed in 1996 and following two years of refinement, a three-part dossier to further reduce pollution from road transport in the Community was agreed, in 1998, by the European Parliament and the Council of Environment Ministers. The three dossiers cover:

- measures to be taken against air pollution by emissions from passenger cars (amendment of Directive 70/220/EEC);

- measures to be taken against air pollution by emissions from light commercial vehicles (pick up trucks, delivery vans etc.), amending the same Directive;

- the quality of petrol and diesel fuels (amendment to Directive 93/12/EC).

Overall the Auto Oil program has five sections:

- fuel quality;

- emissions from private cars;

- emissions from light commercial vehicles;

- emissions from heavy goods vehicles;

- adaptation of provisions relating to roadworthiness testing.

More specifically, the directives aim at:

- controlling those parameters in the composition of petrol and diesel that influence the level of atmospheric emissions, in particular sulphur, benzene, aromatics and lead;
- reducing the limit values for certain pollutants in new vehicle models being brought onto the market.

- In addition, improved control of the day-to-day emissions of vehicles in use is to be achieved by the

mandatory fitting of on-board diagnostic systems, the introduction of a new testing procedure and a new test to limit evaporative emissions.

The resulting directives are interlinked, as the quality of fuel has a significant impact on emissions. The standards for passenger cars and Class 1 light commercial vehicles are identical. However, heavier light trucks in classes 2 and 3 have more lenient standards in relation to their weight.

\section{Fuel efficiency of vehicles}

It would be reasonable to think that fuel efficiency has a dominant role to play in the emission trends of vehicles and within that, the emission trends of road freight vehicles. Its influence is indeed significant but we have to be aware of the Jevons paradox, which might alter the final effects and might change the first expectations. One would logically think that better fuel efficiency would lead to lower fuel consumption and thus designing more fuel efficient vehicles would lead to a drop in the quantity of absolute fuel consumption. This in turn would reduce the negative environmental effects of road transport and lower the emission of greenhouse gases. Let us now look at the Jevons paradox which shows a different aspect of the question. William Stanley Jevons has made an observation in his work The Coal Question [4]. He has discovered that although the industrial usage of coal has become more efficient (thus more products could be produced by using one unit of coal) the absolute quantity of coal used has increased. At least two potentially complementary explanations of this paradox could exist. First, according to classic economics more efficient coal usage reduces the cost of coal for one product. Due to the decrease in price the producers see coal as a more desirable source of energy and so invest into technologies that use coal. The other explanation comes from political economics. According to this, the driver behind production is the profit which urges the industry to enhance efficiency (by reducing the resources used to produce one unit of output) and at the same time increasing the return by producing more and more products and services which leads to the increase in the resources used. Looking at the change in the fuel efficiency of cars and the absolute fuel consumption York has discovered the same phenomenon [5]. He examined the change of fuel efficiency of private cars and light trucks in the United States where fuel efficiency is regulated by CAFE (corporate average fuel economy) standards. The introduction of these values are much disputed though among the representatives of the automotive industry as they promote the design and production of more efficient vehicles, i.e. often smaller vehicles with smaller engines, which are expected by the consumers to be less expensive, while manufacturing these cars is just as costly as the production of the not so 
environment friendly vehicles. In consequence they are not so cost efficient for the industry [6]. Nevertheless these standards which calculate fleet fuel economy by a harmonic mean - have contributed to fuel economy and have been used as the basis of calculation to prove the effect of Jevons paradox in the field of fuel efficiency. The CAFE value of light trucks was found to be $20.6 \mathrm{mpg}$ (approx. $8.8 \mathrm{~km} / \mathrm{l}$ ) in 1984, and increased slightly to $21 \mathrm{mpg}$ (approx. $8.9 \mathrm{~km} / \mathrm{l}$ ) in 2001. But their average weight has augmented significantly in the same period, from 3804 pounds (approx. $1725 \mathrm{~kg}$ ) to 4501 pounds (approx. $2040 \mathrm{~kg}$ ). Thus the fuel efficiency has also increased considerably in the same period: from 78364 p-m/g (approx. $15100 \mathrm{~kg}-\mathrm{km} / \mathrm{l}$ ) to 94521 p-m/g (approx. $18200 \mathrm{~kg}-\mathrm{km} / \mathrm{l})$. This means that the fuel efficiency of light trucks has increased by $20.6 \%$ in the reference period. The same calculations for private cars show a growth of $16 \%$ in fuel efficiency (see Fig. 1).

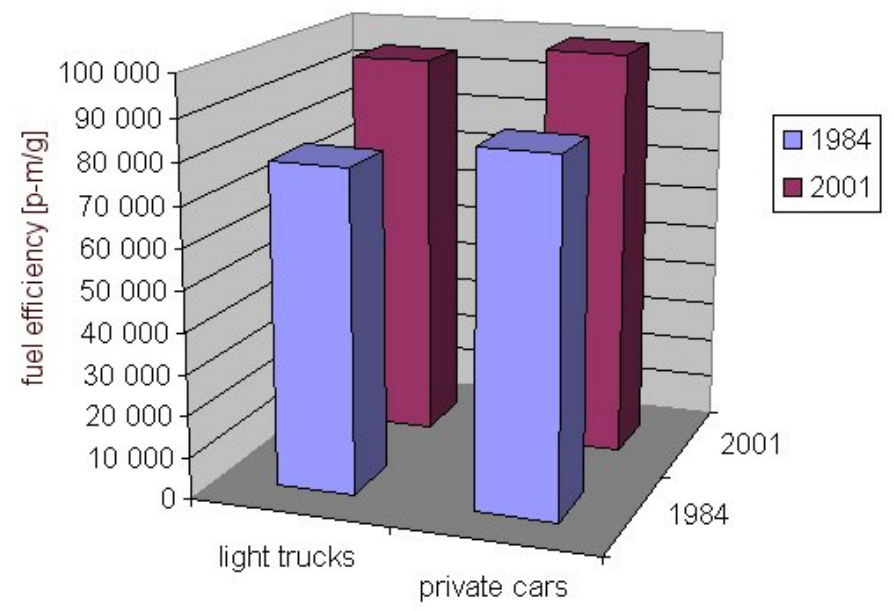

Fig. 1. The change of the fuel efficiency of light trucks and private cars (Source: created by the authors on the basis of [5])

It can be concluded that more efficient engines and streamlined car-bodies have reduced the quantity of fuel used by the individual vehicles. But research shows that this process has not led to a decrease in fuel consumption, quite to the contrary: the rate of the more fuel consuming light trucks among the vehicles has grown from $24.4 \%$ to $46.6 \%$ in the same period. Also the average distance covered by road annually has increased from 15 000 kilometres to 19000 kilometres in the reference period, just as well as the number of vehicles per capita has also increased considerably. Utilisation of biofuels could be a way of reducing $\mathrm{CO}_{2}$ output. The role of the alternative and advanced fuels will be increasing in the next years, but the hegemony of traditional fuels will not broken expectedly [11].

Consequently looking at the trend of fuel consumption it is evident that the absolute consumption augmented as fuel efficiency prompted car users to utilize their vehicles even more often and more inhabitants opted for buying and using cars.

\section{Coupling $\mathrm{CO}_{2}$ emissions with the units of trans- ported goods}

The conventional method to assign the emitted amount of $\mathrm{CO}_{2}$ to transported goods is carbon footprint labelling. However this method is not precise enough since the values of emission are calculated on the basis of statistic data even before the transportation takes place. A new possibility seems to emerge for the solution of the above mentioned problem with the advent of real time assignment of $\mathrm{CO}_{2}$ emissions. The aim of the new method is to couple fuel consumption with the transported good units using RFID systems. This enables a much finer allocation and the would be customers could be provided with the opportunity to choose not only on the basis of price but also on the basis of the environmental burden caused by the system.

This can be even more important in the view of the notion of "freight integrator" introduced in 2001 by the White Paper about the European transport policy of the European Union. The freight integrator is a transportation service provider who organises door-to-door transport choosing without prejudice the most effective and most sustainable combination of transport modes. For the freight integrator it would be of outstanding importance to be able to select not only the cheapest but the most sustainable transport route and mode [8]. Multicriteria decision support tools have been developed to assist the freight integrator in his work (e.g. [9]) and as input these need precise numbers that indicate the environmental effect of a given transport operation. The real time $\mathrm{CO}_{2}$ emission assignment system can be directly used for that.

The emission of $\mathrm{CO}_{2}$ is a function of traffic, of the delivery routes, of the weight of the transported goods, of the types of trucks used and the behaviour of the drivers. These all have to be taken into account when we want to couple the emission to the transported goods. To achieve this goal the real time $\mathrm{CO}_{2}$ emission assignment system is divided into 3 subsystems: the information system, the RFID-tag information system and a calculation system (see Fig. 2 for the detailed structure of the system). The information system is dedicated to get the data of the fuel consumption of the trucks in each driving status and subsequently using this and the delivery route to calculate the $\mathrm{CO}_{2}$ emission in real time. The delivery route is divided into sections, the system calculates the fuel consumption for each section. The start and end points are presently determined manually but this could be automated in the future. The RFID-tag information system is responsible for the collection of data about the loads. To achieve this RFID tags need to be fixed to the goods and the vehicle has to be provided with reader/writer and an antenna. The information system and the RFID-tag information system is connected by Ethernet communication and they feed information into the calculation system and a database. The information is summarized here and the $\mathrm{CO}_{2}$ emissions are allocated to the transported goods [7]. A case study has been conducted to analyze the efficiency of the system explained above. Differ- 


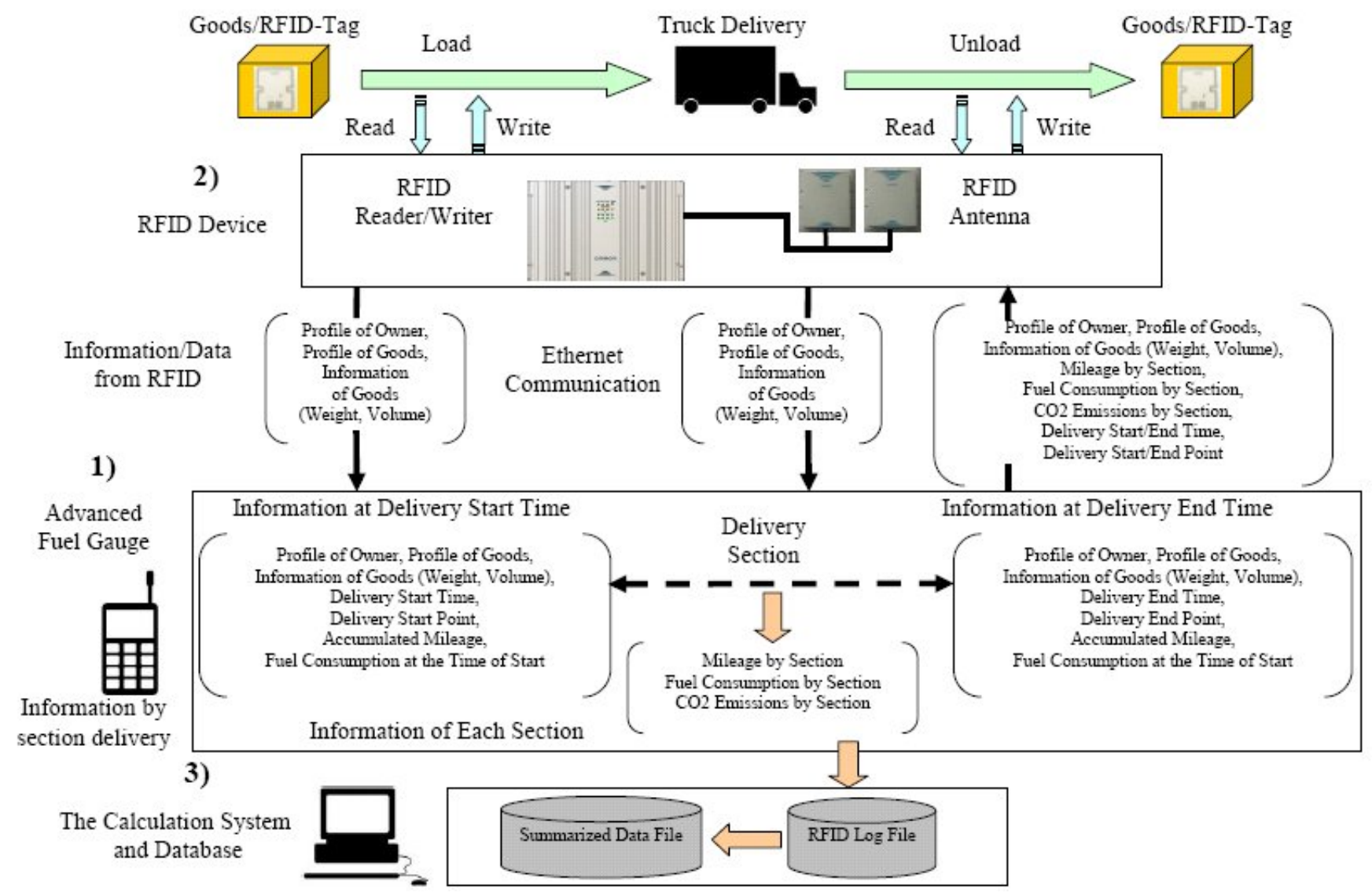

Fig. 2. Overview of the real time $\mathrm{CO}_{2}$ emission assignment system [7]

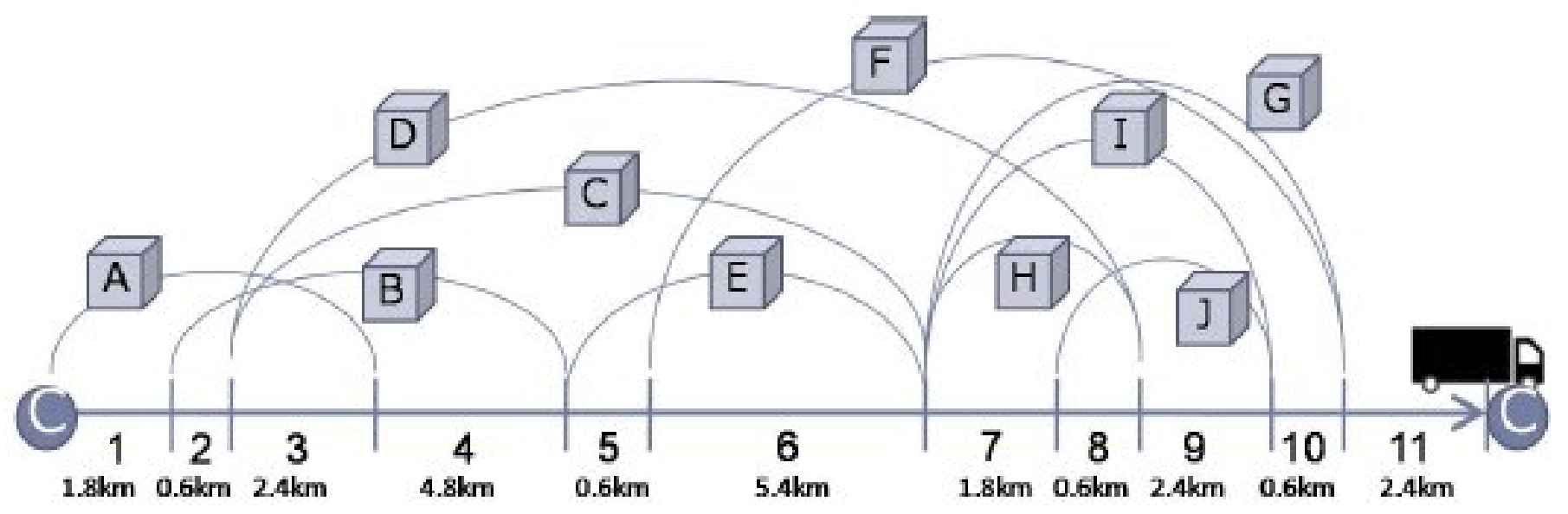

Fig. 3. Experiment condition (mixed loading) [7]

ent packages have been delivered to different distances (Fig. 3, and the $\mathrm{CO}_{2}$ emission have been modelled. Fig. 4 summarizes the results obtained with the conventional (ton-km) method and those of the new method.

\section{Remaining challenges}

While substantial progress has occurred in reducing vehicle emissions and further improvements in air quality are expected in coming years in most major industrialised countries, significant problems remain which require additional action beyond that noted above. The greenhouse gases most closely identified with the transportation sector include carbon dioxide $\left(\mathrm{CO}_{2}\right)$, nitrous oxide $\left(\mathrm{N}_{2} \mathrm{O}\right)$ and methane $\left(\mathrm{CH}_{4}\right)$. However, it is important to note that other vehicle related pollutants contribute to global warming although their quantification has been more difficult. These include $\mathrm{CO}, \mathrm{NMHC}$ and $\mathrm{NO}_{2}$. The road transport sector has stood out in recent years as one of the few sectors in the Union experiencing $\mathrm{CO}_{2}$ emissions growth.

\section{Conclusion}

Continuing air quality problems from vehicle related pollution have been stimulating innovative pollution control approaches around the world. As these approaches are implemented, steady progress is made in reducing air pollution problems. However, the vehicle population and kilometres travelled by vehicles continues to increase, especially in the new mem- 


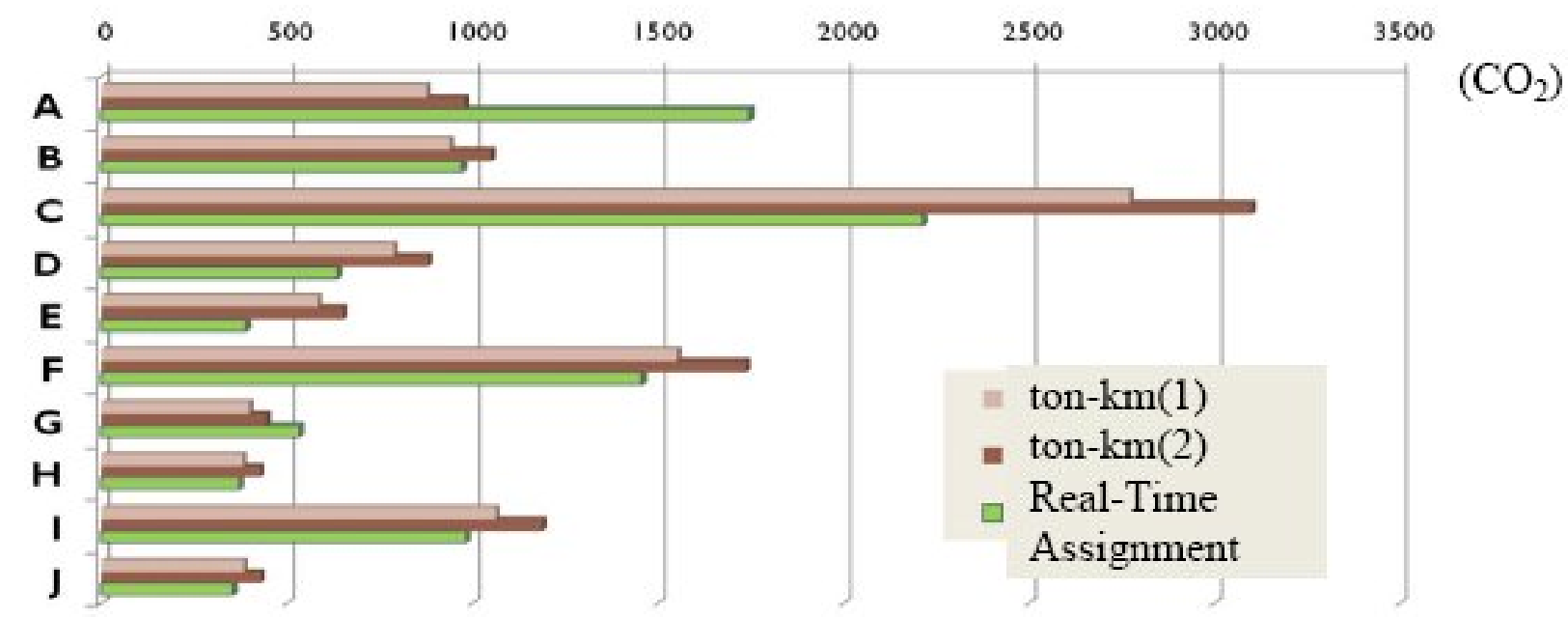

Fig. 4. Result of each assignment $\left(\mathrm{CO}_{2}\right)[7]$

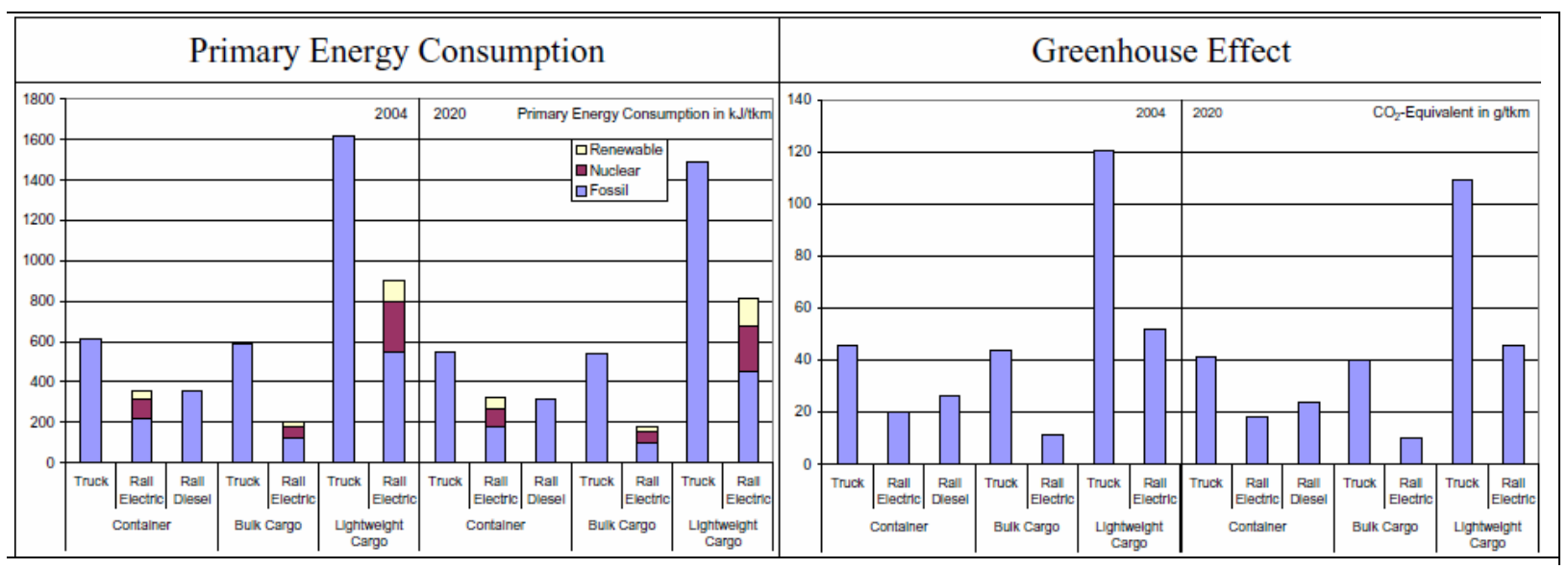

Fig. 5. Comparison of transport modes in freight transport Potential diagram 2004 and 2020 (trend) [10]

bers of the EU. To keep pace with this growth while lowering vehicle pollution even more, the EU is continuing to develop even tighter controls for the coming years. In Europe, European Union light and heavy-duty vehicle and internal combustion engine standards have been substantially tightened over the past few years. It can be concluded that more efficient engines and streamlined car-bodies had reduced the quantity of fuel used by the individual vehicles. But research shows that this process has not led to a decrease in fuel consumption, quite to the contrary: the rate of the more fuel consuming light trucks among the vehicles has grown in the same period. Also the average distance covered by road annually has increased, just as well as the number of vehicles per capita has also increased considerably. Consequently looking at the trend of fuel consumption it is evident that the absolute consumption augmented as fuel efficiency prompted car users to utilize their vehicles even more often and more inhabitants opted for buying and using cars. The emission of $\mathrm{CO}_{2}$ is a function of traffic, of the delivery routes, of the weight of the transported goods, of the types of trucks used and the behaviour of the drivers. These all have to be taken into account when we want to couple the emission to the transported goods. While substantial progress has occurred in reducing vehicle emissions and further improvements in air quality are ex- pected in coming years in most major industrialised countries, significant problems remain which require additional action beyond that noted above.

\section{References}

1 Török Á, Zöldy M, Calculation of the emission surplus of the incoming vehicles in the traffic flow consideration of the international limits, Scientific Review of Transport 9 (2005).

2 Andrias A, Samaras Z, Zierock K H, The Estimation of the Emissions of Other Mobile Sources and Machinery Subparts Off-Road Road Vehicles and Machines, Railways and Inland Waterways In The European Union, September 1994.

3 Diesel Vehicle Emissions and Urban Air Quality, December 1993. Second Report of the Quality of Urban Air Review Group, prepared at the request of the Department of the Environment.

4 Jevons W S, Of the economy of fuel excerpt from The Coal Question, Organization \& Environment 14, no. 1, 99-104.

5 York R, Ecologic paradoxes, William Stanley Jevons and the paperless office in the book "Utilization of energy and the human factor" (2008).

6 Healey J R, Death By the Gallon, USA Today, July 2, 1999, available at http://www.suvoa.org/assets/PDFs/DeathByTheGallon.pdf

7 Yoshifuji T, Goto M, Yamada T, Masui T, Real Time Assignment of $\mathrm{CO}_{2}$ Emissions In Transportation Process - A System Development and Analysis of Information System With RFID, International Symposium on Logistics, August 5, pp. 474-480.

8 Bokor Z, Promoting intermodality in Hungarian transport-logistics system, 
Proceedings of 4th International Logistics and Supply Chain Congress, Izmir University of Economics, 2006, pp. 42-50.

9 Simongati Gy, Multi-criteria decision-aiding model for the evaluation of freight tasks in conformity with sustainability, Scientific Review of Transport (2009), no. 3, 17-29.

10 White Paper: European Transport Policy for 2010. Opinion of the Federal Environment Agency on the mid-term review by the Commission Dessau, November.

11 Zöldy M, Potential future renewable fuel challanges for internal combustion engine, 2009. Jármúvek és Mobilgépek, II.évf. 